\title{
TRANSDISCIPLINARIDADE E EDUCAÇÃO INTERCULTURAL: A FORMAÇÃO DO PROFESSOR INDÍGENA APINAYÉ EM PERSPECTIVA $^{1}$
}

\author{
Severina Alves de ALMEIDA ${ }^{2}$ \\ Francisco Edviges ALBUQUERQUE ${ }^{3}$ \\ Maria José de PINHO ${ }^{4}$
}

RESUMO: Neste artigo, refletimos sobre Transdisciplinaridade e Educação Intercultural, considerando o contexto Apinayé. Os Apinayé são um povo Indígena do norte do Estado do Tocantins. Os aspectos metodológicos estão voltados para uma concepção interdisciplinar, contemplando Estudos Teóricos e Pesquisa de Campo. Para o desenvolvimento do texto, temos duas fases que se complementam. Primeiro fazemos uma revisão da literatura atinente à temática abordada. Para os conceitos de Inter e Transdisciplinaridade, utilizamos as bases teóricas de D’Ambrósio (1997); Fazenda (2003; 2006); Nicolescu (2008; 2009); Damas (2009); Magalhães (2009); e Sommerman (2005). Para Educação Intercultural Ouellet (2002); Banks (1993); Maher (2005; 2006); e Grupioni (2001; 2003). Sobre os Apinayé Nimuendaju (1983); Da Matta (1976); e Albuquerque (1999; 2007; 2009). Acerca da pesquisa do tipo interdisciplinar: Vasconcelos (2009). Sobre Formação de Professores, Tardif (2002) e Pinho (2007). A pesquisa de campo se efetivou mediante uma etnografia com observação participante conforme Erikson (1984); e André (2000). Os dados, coletados, de forma qualitativa, foram gerados mediante diário e notas de campo. Os resultados apontam para uma realidade onde a Transdisciplinaridade se manifesta na prática pedagógica do Professor de Língua Materna Apinayé.

PALAVRAS-CHAVE: Transdisciplinaridade. Educação intercultural. Formação do professor indígena.

\section{Introdução}

Vivenciamos atualmente uma nova ordem em termos de educação escolar. O século XXI segue seu curso e os anseios da contemporaneidade desafiam todos a se enquadraram na emergência de uma sociedade em crise, visível com mais precisão na esfera educacional. É a chamada “Crise Paradigmática”, quando se confrontam dois paradigmas educacionais. De um lado, o "Paradigma Educacional Tradicional” e de outro o “Paradigma Educacional Emergente”, ambos face de uma mesma conjuntura. Já não é

\footnotetext{
${ }^{1}$ Trabalho vinculado à Dissertação de Mestrado: “A Educação Escolar Apinayé na Perspectiva Bilíngue e Intercultural: Um Estudo Sociolinguístico das Aldeias São José e Mariazinha”.

${ }^{2}$ Doutoranda em Linguística. UNB - Universidade de Brasília. Campus Universitário Darcy Ribeiro Pós-Graduação em Linguística. Brasília - DF - Brasil. 70910-900 - ssalvesdealmeida@hotmail.com.

${ }^{3}$ UFT - Universidade Federal do Tocantins. Campus de Araguaina - Departamento de Letras. Araguaina - TO - Brasil.77818-070 - fedviges@uol.com.br.

${ }^{4}$ UFT - Universidade Federal do Tocantins. Campus de Palmas - Departamento de Pedagogia. Palmas TO - Brasil. 77001-090 -mjpinho@uft.edu.br.
} 
mais possível imaginar a educação escolar unilateral, presa a um modelo concebido ainda no século XVIII, tendo como esteio a Revolução Francesa. Urge que se operem mudanças. Outra constatação relevante diz respeito a um processo educativo que deve, necessariamente, trazer novas e valorosas formas de educar. Não é mais admissível uma educação onde o professor é o centro do processo. Nem ele nem os alunos podem assumir tal postura. A emergência de uma educação dialógica irá conduzir essa relação, favorecendo este novo paradigma do ato de educar. Aspectos como união, afeto, solidariedade, reciprocidade, alteridade e amor devem ser incorporados ao processo do ensinar/aprender, e sendo assim, precisam de ser considerados no ato educativo.

Ademais, temos que aprender a aprender, isto é, tirar o melhor proveito das informações que recebemos, assumindo a responsabilidade de que só depende de nós mesmos a apreensão do que nos é direcionado no ato pedagógico. Ato este eminentemente dialógico e que independe de tempo e lugar pré-estabelecidos para se efetivar, mas que requer, necessariamente, cumplicidade e o "querer aprender" por parte do educando. Também devemos considerar o fato de que nos espaços educativos convivem diferentes culturas, promotoras e produtoras de diferentes saberes, que necessariamente imbricam para uma educação Intercultural. Essa nova postura irá nos conduzir a atitudes transdisciplinares, ou seja, modos de convivência com as diferenças que nos levará, consequentemente, a uma convivência onde a aquisição do conhecimento seja algo natural. Afinal, o aprender a aprender se dá numa via de acesso de múltiplos referenciais, onde se entrecruzam diferentes caminhos, convergindo para diferentes formas de aprendizagem.

Essas diferentes formas do ato de aprender encontram no Paradigma Educacional Emergente sua tradução, conforme Maria Cândida Moraes (2004). São formas de aprendizagem que imbricam para a Transdisciplinaridade, onde a Educação Intercultural ancora. Afinal, esse novo Paradigma Educacional, ainda em construção, assim como a Trandisciplinaridade, dão luz à Interculturalidade, razão de ser da escola nos domínios sociais indígenas. Não obstante, é no contexto de uma comunidade indígena, uma realidade intercultural, onde vivem os Apinayé, que esse trabalho se desenvolve. O objetivo é estudar o perfil do professor indígena Apinayé e sua formação, vista numa concepção transdisciplinar. Transdisciplinaridade essa que se estende às práticas pedagógicas de três professores dos anos iniciais do Ensino Fundamental das escolas das aldeias São José e Mariazinha, escolas Mãtyk e Tekator, respectivamente. 


\section{Transdisciplinaridade e educação intercultural: a educação indígena em foco}

Trandisciplinaridade e Educação Intercultural são categorias que se justapõem quando se trata de estudar a educação nos domínios sociais indígenas. Isso porque a educação escolar indígena se apresenta como intercultural, e assim como a Transdisciplinaridade, está em fase de construção, tanto conceitual quando epistemologicamente. Ambas, a Educação Intercultural e a Educação Escolar Indígena se movimentam num espaço intersubjetivo de contradições que imbricam para a Transdisciplinaridade. O ponto de intersecção se dá no momento em que, ao se analisar cada uma dessas categorias, se depara com uma situação aparentemente caótica, identificada mediante um aparato relacional presente num campo gravitacional onde interagem elementos, simultaneamente, antagônicos e proximais. Mas um caos organizado, por mais paradoxal que possa parecer.

Diante dessas implicações, consideramos importante conceituar a Transdisciplinaridade, para nos apoderarmos de seu teor, fazendo um contraponto com outras categorias epistemológicas da mesma amplitude, quais sejam: multidisciplinaridade, pluridisciplinaridade e interdisciplinaridade. Nessa perspectiva, recorremos à seguinte diagramação conceitual, apresentando a Transdisciplinaridade a partir do Modelo de Jantsch: 
Figura 1 - Modelo Jantsch

\section{Transdisciplinaridade - Modelo de Jantsch}

\section{MULTIDISCIPLINARIDADE}

Sistema de um só nivel e de objetivos

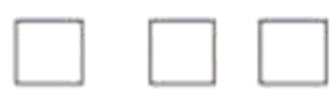

múltiplos; nenhuma cooperação.

PLURIDISCIPLINARIDADE

Sistema de um só nivel e de objetivos múltiplos; cooperação mas sem

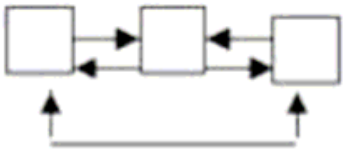

coordenaçâo

INTERDISCIPLINARIDADE

Sistema de dois niveis e de objetivos múltiplos; cooperaçāo procedendo de nivel superior.

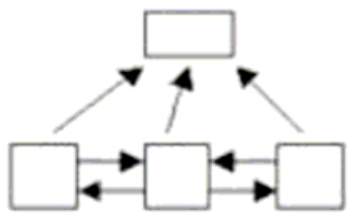

\section{TRANSDISCIPLINARIDADE}

Sistema de niveis e de objetivos múltiplos; coordenação com vistas a uma finalidade comum dos sistemas.

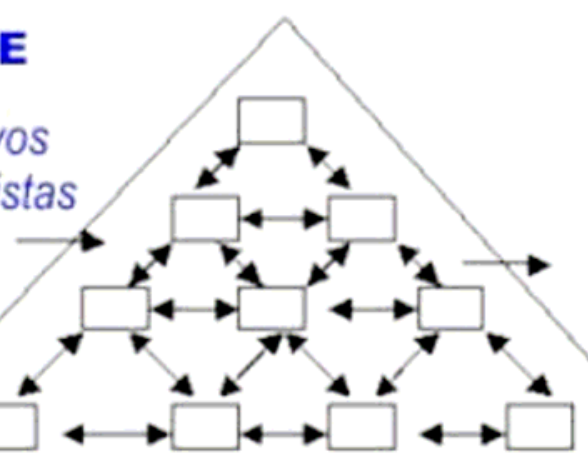

Fonte: Silva (1999, p.6).

Segundo Marinete Aparecida Martins (2009, p.78), no final da década de 1970, no Seminário da Organização de Cooperação e Desenvolvimento Econômico (OCDE), o astrofísico austríaco Erich Jantsch apresentou um modelo de integração entre as disciplinas que congrega os conhecimentos disciplinares: o Modelo de Jantsch (Figura 1). Esse modelo esquemático trata multidisciplinaridade e pluridisciplinaridade separadamente. De acordo com Martins (2009), o modelo demonstra que a multidisciplinaridade constitui o primeiro nível de integração entre os conhecimentos disciplinares. Para essa autora, no ambiente escolar, é no nível multidisciplinar que as 
ações escolares se encaixam, tanto nas atividades como nas práticas de ensino. Contudo, isto não as invalida. Porém, é necessário compreender que há estágios mais avançados que necessitam de ser colocados na prática pedagógica. Lançando um olhar mais atento sobre o modelo esquemático, percebemos que a pluridisciplinaridade é também um sistema de um só nível e de objetivos múltiplos. Entretanto, possui cooperação entre os conhecimentos interdisciplinares com todas as disciplinas se situando no mesmo nível hierárquico, não havendo coordenação de algum nível superior hierárquico.

Quanto à interdisciplinaridade, observamos que esta é um sistema de dois níveis, com objetivos múltiplos e cooperação entre as disciplinas do conhecimento, possuindo uma ação ordenada a um nível superior. Ao analisarmos o Modelo de Jantsch, percebemos que nele a Transdisciplinaridade está num nível hierárquico mais elevado, apresentada por meio de um sistema complexo de vários níveis, com objetivos múltiplos, coordenação de todas as disciplinas do sistema de ensino e uma finalidade comum a todos eles sobre um axioma geral. Para Jantsch (1972 apud WEIL, 1993, p.31), a Transdisciplinaridade "é o reconhecimento da interdependência de todos os aspectos da realidade”. Seria, segundo Weil, um estágio superior da relação interdisciplinar, a qual não se limitaria a interações entre campos do conhecimento especializados, mas que faria uma conexão direta entre o ser e o universo, expressando a relação da humanidade com a natureza de forma harmônica e complementar.

Para Basarab Nicolescu (2008), a Transdisciplinaridade é algo que, de forma sistêmica, perpassa as diferentes disciplinas, indo além de todas as disciplinas que circulam na esfera do conhecimento, sendo sua finalidade a compreensão do mundo atual, para a qual um dos imperativos é a unidade do conhecimento. "Existe alguma coisa entre e através das disciplinas e além de toda e qualquer disciplina? Do ponto de vista do pensamento clássico não existe nada, absolutamente nada. O espaço em questão é vazio, completamente vazio, como o vácuo da física quântica” (NICOLESCU, 2008, p.53).

Todavia, esse mesmo autor, em outro momento, nos informa que diante de vários níveis de Realidade, o espaço entre as disciplinas e além das disciplinas, como o vácuo quântico, está cheio de todas as potencialidades: “da partícula quântica às galáxias, do quark aos elementos pesados que condicionam o aparecimento da vida no Universo" (NICOLESCU, 2009, p.2). O autor enfatiza que a estrutura descontínua dos níveis de Realidade determina a estrutura descontínua do espaço transdisciplinar. Realidade esta que, por sua vez, explica porque a pesquisa transdisciplinar é 
radicalmente distinta da pesquisa disciplinar, da qual é complementar. Para Nicolescu (2009), a pesquisa disciplinar envolve, no máximo, um único e mesmo nível de Realidade; na maioria dos casos, aliás, ela não envolve senão fragmentos de um único e mesmo nível de Realidade. Em contrapartida, a Transdisciplinaridade interessa-se pela dinâmica decorrente da ação simultânea de diversos níveis de Realidade.

A descoberta dessa dinâmica passa necessariamente pelo conhecimento disciplinar. Os três pilares da Transdisciplinaridade - os níveis de Realidade, a Lógica do Terceiro Incluído e a Complexidade - propostos por Nicolescu (2009), determinam a metodologia da pesquisa transdisciplinar. "A disciplinaridade, a pluridisciplinaridade, a interdisciplinaridade e a Transdisciplinaridade são as quatro flechas de um único e mesmo arco: o do conhecimento” (NICOLESCU, 2009, p.9). Segundo Ubiratan D’Ambrósio (1997), a Transdisciplinaridade não constitui uma nova filosofia, nem uma nova metafísica. Tampouco uma ciência das ciências. Muito menos uma nova atitude religiosa. Para esse autor, em todas as culturas o conhecimento está subordinado a um contexto natural, social e de valores. Indivíduos e povos criam, ao longo da história, instrumentos teóricos de reflexão e observação. Associados a estes, desenvolvem técnicas e habilidades para explicar, entender, conhecer e aprender, visando ao saber e ao fazer. Assim, teorias e práticas são respostas a questões e situações diversas geradas pela necessidade de sobrevivência e transcendência. D’Ambrósio (1997), entende que a Transdisciplinaridade é o reconhecimento de que não há espaço nem tempo privilegiados que permitam julgar e hierarquizar - como mais corretos ou verdadeiro complexos de explicações e de convivência com a realidade.

No tocante à Educação Intercultural, qual sua implicação no campo de estudos transdisciplinares voltados para a educação? Começamos com outra pergunta: O que é realmente uma Educação Intercultural? Do ponto de vista epistemológico, podemos dizer que é uma educação que se desenvolve num ambiente onde interagem diferentes culturas ou, segundo Luiz Donizete Benzi Grupioni (2001, p.87), “é uma educação onde se faz presente a diversidade de culturas e a riqueza de conhecimentos, saberes e práticas a elas associadas”.

Segundo Fernando Ouellet (2002), o conceito de educação intercultural designa toda a formação sistemática que visa a desenvolver melhor compreensão das culturas nas sociedades modernas; maior capacidade de comunicação entre pessoas de culturas diferentes; atitudes mais adaptadas ao contexto da diversidade cultural, através da compreensão dos mecanismos psicossociais e dos fatores sociopolíticos capazes de 
produzir racismo; maior capacidade de participar na interação social, sendo esta vista como criadora de identidades e promotora de sentido de pertença comum à humanidade (OUELLET, 2002). Sendo assim, é incontestável o caráter Transdisciplinar da Educação Intercultural. Não obstante, a Educação Intercultural, enquanto instrumento que nos ajuda a interferir e a intervir no mundo que nos rodeia, inscreve-se numa perspectiva mais ampla, como é o caso da educação para a cidadania, onde a coesão social aparece associada à valorização da diversidade.

Segundo Grupioni (2006) a escola, enquanto instituição surge para os povos indígenas a partir do contato. "Impondo-se por meio de diferentes modelos e formas, cumprindo objetivos e funções diversas, a escola esteve presente ao longo de toda história de relacionamento dos povos indígenas com representantes do poder colonial e, posteriormente, com representantes do Estado-nação” (GRUPIONI, 2006, p.43). Para esse autor, como num movimento pendular, pode-se assegurar que a escola se moveu, num longo percurso, do passado aos dias de hoje, de algo que foi imposto aos indígenas a uma demanda, que é atualmente por eles reivindicada. “Utilizada, no passado, para aniquilar culturalmente estes povos, hoje tem sido vista como um instrumento que pode lhes trazer de volta o sentimento de pertencimento étnico, resgatando valores, práticas e histórias esmaecidas pelo tempo e pela imposição de outros padrões socioculturais” (GRUPIONI, 2006, p.44). Para Terezinha Machado Maher (2006), como a escola concebida nos padrões ocidentais entra nas aldeias em decorrência do contato com o outro, com os não índios, a questão da interculturalidade, isto é, “do conseguir fazer dialogar comportamentos e conhecimentos construídos sob bases culturais distintas e frequentemente conflitantes, é atualmente entendida como o esteio, a razão de ser da escola indígena” (MAHER, 2006, p.94).

Essa autora acredita que o desafio posto pela interculturalidade não pode, nesse contexto, ser entendido como um enriquecimento, como um bônus - como parece ser o caso na maior parte das escolas não indígenas - porque o investimento no estabelecimento do diálogo intercultural é o alicerce, é o que justifica mesmo a existência dessa escola, é o que dá a ela relevância política. Ainda refletindo junto a Maher (2006, p.94) perguntamos: Será que em um mundo tão globalizado como o de hoje, nossas escolas - principalmente aquelas dos grandes centros urbanos - também não deveriam adotar mais categoricamente a interculturalidade como tema transversal, para melhor preparar nossas crianças e jovens para o sempre difícil encontro com o outro, com o diferente, com a alteridade? 
Não tem como não concordar com essa autora. Devemos sim, estender os estudos interculturais para as escolas de nossa sociedade. Torna-se imperativo que se estude as culturas dos povos indígenas, assim como dos afro-descendentes. Mas, para isso é fundamental que se debata os avanços advindos de pactos nacionais e internacionais, conforme preconiza Lopes da Silva e Grupioni (2000). Nesse sentido, lembramos que foi promulgada em 10 de março de 2008 a Lei 11.645 (BRASIL, 2008), que altera a Lei $\mathrm{n}^{\text {o }}$ 9.394, de 20 de dezembro de 1996, modificada pela Lei $\mathrm{n}^{0}$ 10.639, de 9 de janeiro de 2003, que estabelece as diretrizes e bases da educação nacional, para incluir no currículo oficial da rede de ensino a obrigatoriedade da temática "História e Cultura AfroBrasileira e Indígena”, e deve acontecer ao se ministrar, preferencialmente, as disciplinas de história e de literatura.

\section{Marcos transdisciplinares na educação: o professor indígena e sua formação}

\section{Os Apinayé}

Os Apinayé são uma sociedade indígena remanescente da grande nação Timbira que ocupavam, nos séculos passados, os cerrados do norte de Goiás, sul do Maranhão e do Piauí, os quais foram expulsos progressivamente pelas frentes de penetração agropastoris. Habitando uma região de transição entre o cerrado e a Amazônia Brasileira, esses indígenas ocupam 27 aldeias, mantendo autonomia sobre as terras em que vivem e trabalham, numa área delimitada e homologada pelo decreto 90.960 de 14/02/1985 (BRASIL, 1985), com extensão de 141.904 há, numa região conhecida como "Bico do Papagaio". Esse povo mantém uma situação de contato com a sociedade envolvente bastante estreita, estabelecendo relações comerciais, principalmente com a venda de coco babaçu e excedentes da produção agrícola.

Segundo Albuquerque (1999, p.8), os Apinayé começaram a ser integrados à história do Brasil com a ocupação do sertão nordestino e com a intensificação da navegação do rio Tocantins. A ocupação do sertão do Maranhão, da Bahia e do Piauí é consequência da criação extensiva de gado que, no período Colonial, servia para alimentar as populações dos engenhos litorâneos. Esse gado, porém, avançou pelos sertões até chegar ao sertão goiano, atual Tocantins, na região onde se achavam os índios. A frente pastoril é como salienta Melatti (1993 apud ALBUQUERQUE, 1999, p.9), caracterizada pela criação de gado que avança pelos territórios indígenas, a fim de 
tomar suas terras para usá-las na expansão do rebanho. Todavia, a situação de contato entre os Apinayé e a sociedade envolvente é complexa e permeada por valores que parecem estar diretamente relacionados com o tipo de produto basicamente explorado na região, com o tempo de sua ocupação, com as agências de contatos e a sociologia dos aglomerados regionais, urbanos e rurais. Segundo Da Matta (1976) isso "não significa que é possível justificar as arbitrariedades sempre cometidas contra os índios, como por exemplo, a sua permanente falta de assistência médico-sanitária”.

\section{Educação Transdisciplinar e a formação do professor indígena: o contexto Apinayé}

Figura 2 - Mafalda
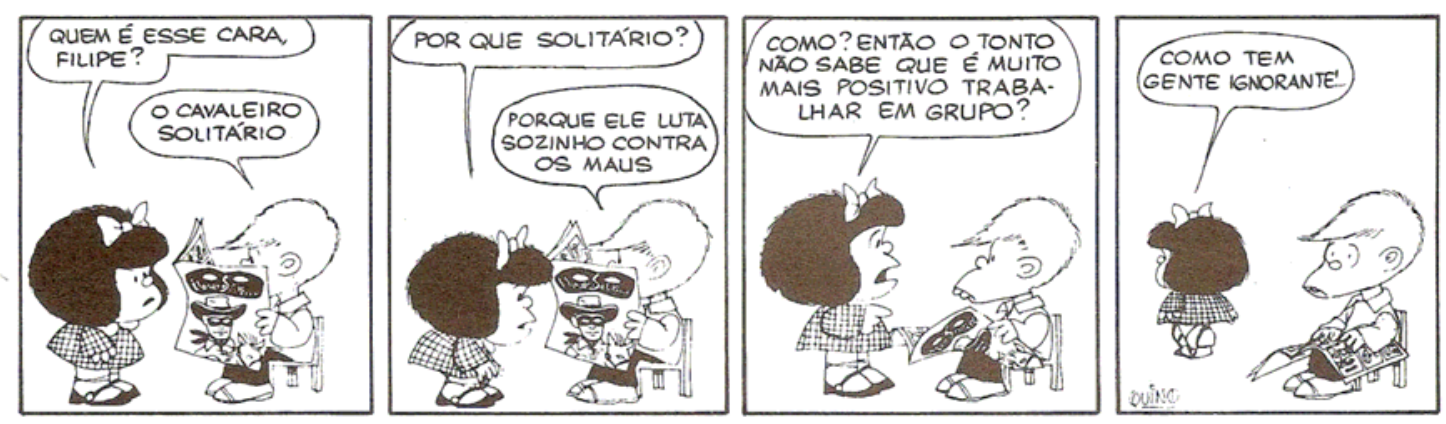

Fonte: Disponível em: <www.todamafalda.com.br>. Acesso em: 2 jan. 2011.

A escolha de uma tirinha de Mafalda $^{5}$ para dar continuidade a nossa reflexão acerca da Transdisciplinaridade no contexto educacional, nomeadamente no que concerne à formação do professor Apinayé, não aconteceu por acaso. Esta simpática personagem, que faz parte da vida de muitas pessoas há mais de cinquenta anos, está cada dia mais atual. Ela traduz o pensamento de seu criador com abordagens temáticas que nos leva a refletir contextos multirreferenciais. Um destes contextos é a Transdisciplinaridade na educação, desde que sua efetivação se dá, necessariamente, por meio de uma cooperação mútua. Nesse sentido evocamos Jacques Delors (1998), que em seu relatório “Educação um Tesouro a Descobrir”, traz os quatro pilares de um novo paradigma de educação que deve orientar o processo de ensino e de aprendizagem no século XXI, quais sejam: aprender a conhecer, aprender a fazer, aprender a viver junto e aprender a ser. A estes, o

\footnotetext{
${ }^{5}$ Menina de 7 anos, que vive em Bueno Aires, na Argentina, Mafalda é uma personagem das histórias em quadrinhos do cartunista Quino.
} 
autor incorpora as sete colunas da evolução “Transdisciplinar na Educação”, sendo a primeira destas a "Educação Intercultural e Transcultural”.

Com efeito, a Transdisciplinaridade está presente nos domínios interculturais e sociais indígenas, evidenciada na educação que as crianças das aldeias recebem desde cedo. É uma educação advinda dos ensinamentos dos mais velhos, e que os professores indígenas buscam incorporar às suas práxis pedagógicas. Nessas sociedades são bem nítidas duas formas de educar. A Educação Indígena, pautada na ancestralidade e em valores transmitidos por meio da oralidade, específica a cada povo, e a Educação Escolar Indígena, que nada mais é do que a educação formal das sociedades ocidentais adaptadas, e de caráter assimilacionista (MAHER, 2005), para os povos indígenas.

Segundo Hildonice de Souza Batista (2011), na Educação Indígena as crianças aprendem a lidar com a natureza de forma complementar e harmônica; aprendem que a fitoterapia - a cura através das plantas — é algo indispensável para a saúde de cada indivíduo da aldeia, muito mais até que os remédios alopáticos; aprendem que existe uma cura espiritual, tão ou mais importante do que um tratamento recomendado por um médico, onde o Cosmo é o grande Mestre; aprendem que a terra generosamente cede o alimento necessário para a sobrevivência. Mas que precisa de ser cuidada para que isso ocorra. Aprende que vem dos rios a água que da natureza emana produzindo vida. Tudo isso estabelece um elo entre o homem e o universo, num dialogar com mitos e ancestrais, incorporando valores axiológicos capazes de transpor a tênue fronteira entre o físico e o espiritual, o sagrado e o profano.

Já na Educação Escolar Indígena o que se percebe é a imposição de um modelo educativo pautado em normas coercitivas de cunho alienante. Uma educação homogeneizadora, onde o currículo está a serviço do grupo que detém o poder, nesse caso, a sociedade envolvente. Esta estrutura social é vista por Pierre Bourdieu (1992) como um processo homogeneizador e mantenedor das relações de poder e, por conseguinte, num conhecimento científico estático, imutável, inquestionável. Todavia o que acontece no espaço das aldeias quando se trata de educar as crianças e jovens a partir dos ensinamentos próprios da comunidade, é uma relação de contra-hegemonia, de contra-poder, de contra-indução de conhecimento, buscando educar para uma vida de

\footnotetext{
${ }^{6}$ As outras seis colunas são: Diálogo entre arte e ciência; Educação inter e trans-religiosa; Integração da informática na educação; Educação transpolítica; Educação transdisciplinar; Relação transdisciplinar.
} 
partilha e solidariedade. Numa intersecção entre homem e natureza, os indígenas vão questionando a educação que lhes é forçada. Vejamos a fala desse professor ${ }^{7}$ :

[...] Os índios têm sua educação que é a da aldeia. Aqui a criança aprende o que a escola não ensina que é como viver na aldeia. Os mais velho são professor, a mata é professor, o rio é professor. A escola dos branco não ensina como viver na aldeia. Ensina a ler e escrever o que também é bom porque ensina como viver no mundo dos branco. Mas o índio vive no mundo dos índio. Tem coisa que o branco não sabe nem sua escola ensina. Por isso é importante a educação dos índios que ensina que a natureza é mais importante que qualquer homem, e que sem ela o homem morre (JOÃO, PROFESSOR DA ESCOLA MÃTYK DA ALDEIA SÃO JOSÉ).

Uma educação que preserve a vida e prepare o indivíduo para viver em consonância com os ditames da natureza, é o que apreendemos da fala desse professor. Isso ele identifica nos ensinamentos que são passados pelos mais velhos. Ensinamentos estes que asseveram uma Transdisciplinaridade traduzida numa educação onde o utilitarismo não tem vez. Segundo Batista (s/d), os indígenas aos pouco vão descobrindo que a educação da sociedade envolvente se faz necessário, mas que não é o único caminho. Para essa autora, agindo assim estes povos instauram uma resistência que têm como esteio o querer, o fazer e o ser do povo indígena, no próprio espaço sócio-cultural dominante, ou seja, na própria trama do poder. Nesse sentido, o educar numa concepção transdisciplinar perpassa o campo interdisciplinar, produzindo modos de compartilhar saberes, reconhecendo os diferentes níveis de realidade, ultrapassando o território científico, criando, segundo Edgar Morin (2002), Luiz Antônio Damas (2009) e Solange M. O. Magalhães (2009), espaços de diálogos multirreferenciais com as diversas culturas, com a vida de cada grupo humano, abrindo possibilidades de visões plurais a respeito de um fenômeno ou conceito, ou a respeito da complexidade da própria vida.

\section{A Formação do professor indígena Apinayé}

Maher (2006, p.24) sustenta que é só a partir da década de 1970, que se percebe, no Brasil, a importância de uma escolarização formal de alunos indígenas conduzida pela própria comunidade. A autora informa ainda que é nessa época que os primeiros Programas de Formação de Professores Indígenas foram implementados no País por organizações não-governamentais. Esses poucos programas pioneiros, no entanto,

\footnotetext{
${ }^{7}$ Visando a preservar a identidade de nossos interlocutores, optamos por usar pseudônimos.
} 
fizeram escola e rapidamente começaram a surgir, em todas as regiões do país, mais e mais programas de formação para o Magistério Indígena. Durante as décadas de 1980 e 1990, um conjunto de medidas legais fez com que as questões que envolvem a Educação Escolar Indígena passassem a fazer parte do rol de responsabilidades do Estado e, hoje, vários dos Programas de Formação de Professores Indígenas são geridos por secretarias estaduais de educação. A maior parte desses programas se desenvolve no âmbito do ensino médio, embora já existam iniciativas visando a uma formação específica em nível superior. Os Cursos de Licenciatura para professores indígenas, isto é, Cursos de Licenciatura Intercultural, promovidos pela Universidade do Estado de Mato Grosso (UNEMAT), Universidade Federal de Roraima (UFRR), Universidade de São Paulo (USP) e Universidade Federal de Goiás (UFG), são apenas quatro exemplos dessa nova tendência.

Mas o que caracteriza um programa de formação de professores indígenas? Quais são as suas especificidades? No que programas dessa natureza diferem, enfim, de outros programas de formação para a docência? Segundo Maher (2006), devemos considerar o fato de que, enquanto cabe ao professor não índio formar seus alunos como cidadãos brasileiros plenos, é responsabilidade do professor indígena não apenas preparar as crianças, os jovens e os adultos, sob sua responsabilidade, para conhecerem e exercitarem seus direitos e deveres no interior da sociedade brasileira, mas também garantir que seus alunos continuem exercendo amplamente sua cidadania no interior da sociedade indígena à qual pertencem.

É por esse motivo, então, que os professores indígenas, em seu processo de formação, têm que, o tempo todo, refletir criticamente sobre as possíveis contradições embutidas nesse duplo objetivo, de modo a encontrar soluções para os conflitos e tensões daí resultantes. Apenas a guisa de exemplo: é costume, em várias sociedades indígenas, manter reclusas suas adolescentes durante o período que antecede a primeira menstruação. Elaborar um calendário escolar que garanta, ao mesmo tempo, o desenvolvimento, por parte das jovens alunas indígenas, das competências acadêmicas desejadas e o respeito a esse tipo de prática cultural ilustra apenas um dos inúmeros desafios postos aos professores indígenas em seus cursos de formação. (MAHER, 2006). Com efeito, a expectativa em torno da formação desse profissional é que ele, além de ser professor de sua escola, deva ser também um agente de comunicação entre sua comunidade e a sociedade envolvente, o que não deixa de ser um grande desafio que envolve, de um lado, investimentos na sua formação individual e específica e, do outro, 
a comunidade indígena que ele representa. Esta, por sua vez, deve participar ativamente das discussões, dos objetivos e das práticas da escola indígena local, bem como dos programas de formação e qualificação de seus professores. Afinal, uma das excelências da educação intercultural indígena é o envolvimento dos mais velhos e lideranças da aldeia nos assuntos da escola, desde que estes são figuras centrais na educação de sua população, que se dá de forma efetiva também fora da sala de aula, ou seja, na comunidade.

De modo geral, esses processos de formação possibilitam que os professores indígenas desenvolvam competências que lhes permitam atuar, de forma responsável e crítica, nos contextos interculturais e sociolinguísticos nos quais as escolas indígenas estão inseridas. Entretanto, em diversas situações, cabe aos professores que lecionam nessas escolas atuarem como mediadores e interlocutores da comunidade com os representantes do mundo de fora da aldeia, e com a sistematização e organização de novos saberes e práticas (GRUPIONI, 2003). Consequentemente compete a esses professores a tarefa de refletir criticamente sobre sua própria formação, criando estratégias para que se promova a interação dos diversos tipos de conhecimentos que se apresentam e se entrelaçam no processo escolar. Observando que, de um lado, encontram-se os conhecimentos ditos universais, a que todo estudante, indígena ou não, deve ter acesso. E, de outro, os conhecimentos étnicos próprios ao seu grupo, que, se antes eram negados, hoje assumem importância crescente nos contextos escolares.

Todavia, como temos duas categorias de professores bem específicas atuando nessa realidade, ou seja, o professor de língua materna nativo da aldeia e o professor que não é indígena é preciso considerar alguns fatores. Primeiro, tem o professor indígena que faz parte da comunidade e que domina plenamente seu idioma, mas não domina inteiramente o português. Segundo, existe o professor que vem de fora o qual, por sua vez, nada sabe da língua falada por seus alunos, conforme observamos em nossa pesquisa nas escolas Mãtyk e Tekator das aldeias Apinayé. Dessa forma percebe-se que a situação do professor que vem de fora é mais complicada, pois a comunicação, fator primordial para que a aprendizagem ocorra, está comprometida. Sendo assim, é imperioso que exista algum planejamento no sentido de preencher essas lacunas, ou seja, um intercâmbio entre as escolas indígenas e os órgãos responsáveis pelo monitoramento e avaliação dessas instituições, realizando um trabalho de preparação prévia visando à consecução de uma escola que atenda às necessidades da comunidade em que se insere. E isso implica necessariamente na formação desse professor. 
Como sabemos, a formação do professor é uma questão de política pública, e como ta deve ser entendida. Segundo Maria José de Pinho (2007, p.144) “uma proposta efetiva de formação de professores exige uma ação conjunta entre o governo federal, estadual e municipal e os profissionais da educação para que sejam implantadas políticas concretas de profissionalização e valorização docente”. Para essa autora, não podemos esquecer que essas políticas, necessariamente, devem contemplar não só condições dignas de trabalho, mas também plano de careira, progressão funcional e salário justo. Sem esses elementos, será impossível elevar a auto-estima e a imagem social do professor.

Com efeito, ao estudarmos os professores Apinayé, percebemos que eles padecem dos mesmos anseios e das mesmas necessidades e carências de todo professor brasileiro, e por vezes sua situação é até mais complicada. Eles fazem o que fazem não apenas pelo salário que ganham. Mas apesar de viverem numa comunidade indígena, terem um currículo imposto por técnicos insensíveis às suas realidades, "não terem plano de carreira, progressão funcional e salário justo” (PINHO, 2007, p.144), identificamos em suas práxis pedagógicas características transdisciplinares. Esses professores, com atitudes simples, rompem com os ditames do Paradigma Educacional Tradicional visto por Moraes (2004, p.6), como aquele que se baseia no conhecimento “objetivo” adquirido pelo experimento e na observação controlada, buscando o critério de verdade na experimentação (sensação) e na lógica matemática (razão). Em contrapartida, na ação dos professores Apinayé identifica-se um novo paradigma, que nos traz a percepção de um mundo complexo, a visão de contexto, uma visão mais ampla e abrangente, destacando a compreensão ecossistêmica da vida que enfatiza as relações do todo com as partes. Para Moraes, esta:

[...] é uma visão ecológica que reconhece a interdependência fundamental de todos os fenômenos e o perfeito entrosamento dos indivíduos e das sociedades nos processos cíclicos da natureza. Através desta percepção ecológica, podemos reconhecer a existência de uma consciência de unidade da teia da vida, a interdependência de suas múltiplas manifestações, seus ciclos de mudanças e de transformações (MORAES, 2004, p.13). 
Nessa concepção a Transdisciplinaridade se faz notar na práxis pedagógica dos professores indígenas Apinayé, a partir de sua formação. Vejamos a fala dessa professora $^{8}$ :

[...] quando comecei a ensinar eu não sabia muito bem o que fazer. Não tinha nenhuma teoria para me ajudar. Então eu fazia como eu tinha aprendido. E veja que eu não tinha aprendido muita coisa. E o material de ensino vinha dos professores que tinha ensinado na turma do ano anterior. Tudo era repetido. As criança não gostava da aula. Não aprendia nada. Isso me deixava triste. Eu via que essas aula não funcionava. E eu tinha que dar aula na língua, mas com material em português. Tudo era mais difícil. Eu não sabia que eu podia mudar o jeito de dar aula. Era só cópia e conta. Então eu fui fazer o curso de Goiânia. E vi que eu podia fazer uma aula diferente. Porque aprendi muita coisa sobre trans...transdisciplina...transdisciplinaridade. É até difícil de falar, mas é fácil de entender. É só fazer com que a aula saia da sala da escola prá fora. No pátio da aldeia, na beira do ribeirão, debaixo do pé de babaçu, em qualquer lugar da aldeia posso fazer essa aula. A natureza, as folha, as formiga, as abelha, os coco, tudo é conteúdo. O vento que bate na gente serve como aula de ciência. Os coco de babaçu ajuda na aula de matemática. Os bicho que aparece na hora ajuda a entender a ecologia, a entender e a preservar o meio ambiente. Esse jeito de ensinar é bem melhor. As criança gosta de estudar assim. E nós gosta de ensinar porque ver que as crianças aprende (GRAÇA, PROFESSORA APINAYÉ, 12/11/2010).

É impressionante como essa professora se apoderou das teorias às quais tem se exposto durante as aulas do curso de Licenciatura Intercultural. Sua predisposição para aplicar o que ela aprende na sua prática cotidiana é louvável. Com ela a complexidade da Inter e da Transdisciplinaridade perde força. Talvez esta simplificação não seja entendida pela academia. Afinal, para muitos teóricos, quanto mais complicado o ato pedagógico, mais eficaz o resultado. Portanto, a atitude dessa professora é antes de tudo um ato de coragem. É comum chegarmos à aldeia e encontrarmos as salas vazias. E isso pode acarretar problemas numa desavisada visita dos técnicos da Secretaria de Educação. "Eu preciso ser responsável pela minha atitude. Sei que é o melhor para as criança. Assim elas aprende mais e faço o diário de classe com os resultado, e é aí que eu vejo os avanço. Os técnico da Secretaria no final tem que entender. Tem que entender” (GRAÇA, PROFESSORA APINAYÉ, 12/11/2010).

Com efeito, por serem atuantes numa comunidade indígena, os professores Apinayé são protagonistas de uma práxis pedagógica que, simultaneamente, incorpora aportes teóricos da Transdisciplinaridade e da Educação Intercultural, isto é, da

${ }^{8}$ Visando a preservar a identidade da professora, daremos um pseudônimo, chamando-a de "Graça". 
Interculturalidade. Isso se deve à situação de contato com outras culturas, e por estarem vinculados a um Curso de Licenciatura Intercultural na UFG - Universidade Federal do Goiás - o qual é destinado aos povos indígenas que se situam na região AraguaiaTocantins. Nesse sentido, consideramos pertinente apresentar algumas notas acerca desse Curso, e trazemos primeiramente uma transcrição de sua Logo-Marca (Figura 3) por considerarmos que aspectos da Transdisciplinaridade se encontram presentes em sua diagramação, o que favorece nossa interpretação acerca da formação do professor indígena, nomeadamente do professor Apinayé:

Figura 3 - Logo-Marca

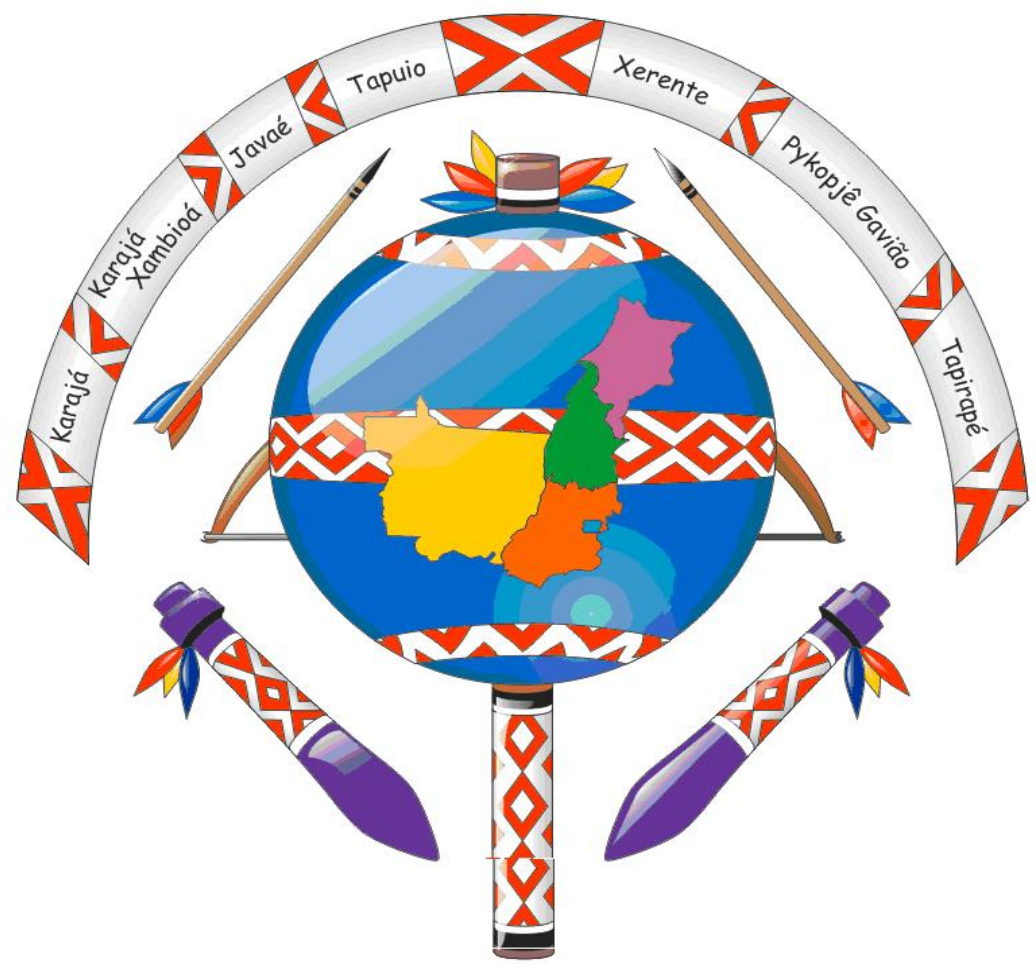

Fonte: Disponível em: <www.ufg.br>. Acesso em: 13 dez. 2010.

A diagramação traz uma composição étnica que integra povos e saberes indígenas brasileiros: Apinayé; Gavião; Guajajara; Javaé; Karajá; Krahô; Krikati; Tapirapé; Tapuio e Xerente. Esta integração de saberes converge para uma possível Transdisciplinaridade na formação desses professores indígenas, desde que interagem aspectos da cultura de cada um deles; conhecimentos específicos de cada povo, dialogando em consonância com a estrutura curricular do curso, cujos temas referenciais - interculturalidade, diversidade e diferença, identidade/etnicidade, autonomia e alteridade - são indicadores de que perspectiva os temas contextuais deverão ser 
trabalhados, sem perder de vista o vínculo entre saberes locais e universais. Para Maurice Tardif (2002, p.33) “o saber docente se compõe, na verdade, de vários saberes provenientes de fontes diferentes. Esses saberes são ao saberes disciplinares, curriculares, profissionais (inclusive das ciências da educação e da pedagogia) e experiências”.

Retomando a questão da interculturalidade, o documento norteador do curso ${ }^{9}$, no item que trata dos “Temas Referenciais das Matrizes” assegura que “a interculturalidade está sendo entendida não apenas como um meio que reconhece o valor intrínseco de cada cultura e defende o respeito recíproco entre elas, mas que propõe também enfrentar os conflitos oriundos desse relacionamento, como também as suas riquezas”. O documento assegura ainda que a "Matriz Formação Básica do Professor é o alicerce da construção das matrizes específicas entendidas aqui como áreas distintas, mas não isoladas umas das outras”, quais sejam: Ciência da Natureza, Ciências da Cultura, Ciências da Linguagem. Estas se originam daquela e com ela dialogam. Na Matriz Formação Básica serão incluídos também os conhecimentos específicos das Ciências Humanas.

\section{Considerações finais}

Neste artigo buscamos refletir sobre a Transdisciplinaridade e a Educação Intercultural tendo em vista o contexto escolar dos Apinayé, povos indígenas que habitam no norte do estado do Tocantins, pertencentes ao grupo Macro-Jê e à Família Linguística Jê. O foco central é a formação do professor indígena que leciona nas escolas Mãtyk e Tekator das aldeias são José e Mariazinha. O estudo, concebido através de uma etnografia com observação participante, é discutido à luz de uma criteriosa revisão bibliográfica. Aspectos da Inter e da Tansdisciplinaridade assumem relevância.

A Interculturalidade é discutida no âmbito da Educação Escolar Indígena, desde que esta é idealizada pela sociedade envolvente, e tem que ser praticada nos domínios sociais indígenas, o que pressupõe que se precisa de enfrentar as barreiras lingüísticas, vivenciada na realidade da fronteira étnica. Nessa perspectiva, estudamos o professor

\footnotetext{
${ }^{9}$ Nas referências ao texto do Documento que regulamenta o Curso de Licenciatura Intercultural da UFG não constam ano e página porque não localizamos em nenhum momento ao examinarmos o documento que está disponível on line: <http://www.ufg.br/this2/page.php?menu_id=2820\&pos=esq\&site_id=115>. Acesso em: 20 jan. 2010. Quando transcrito de acordo com o texto original, a citação está separada por aspas duplas, sem indicação de ano ou número de página.
} 
indígena Apinayé e sua formação, levantando informações acerca do Curso de Licenciatura Intercultural ao qual estão vinculados os professores objeto da pesquisa. Dessa forma percebemos que a Transdisciplinaridade é um dos alicerces que sustenta as bases teóricas do curso que é oferecido pela UFG - Universidade Federal do Goiás.

Constatamos que o professor indígena Apinayé busca formas alternativas no sentido de fazer uma aula contextualizada, onde as teorias apreendidas durante sua formação sejam colocadas em prática. Que as crianças ao serem deslocadas da sala de aula para o ambiente externo, ou seja, a aldeia e seu entorno, têm possibilidade de interagir com a natureza numa dinâmica que aglutina teoria e prática, numa ação educativa que privilegia a formação holística da criança em formação. Que a educação que as crianças recebem de seu povo, deve ser agregada aos conhecimentos historicamente construídos e que são um patrimônio de todos, transmitidos através da escola.

Todavia, percebemos que é conflituosa, mas necessária, a transposição da teoria para a prática quando se trata da Transdisciplinaridade (re)produzida no dia-a-dia da práxis pedagógica, notadamente na realidade da escola que se constrói numa sociedade indígena. Considerando, ademais que, diante da crise de paradigmas que povoa a educação atualmente, é primordial que se estabeleçam redes e teias dialógicas capazes de promover a unidade em meio à diversidade, notadamente no âmbito das relações interétnicas que se apresentam como algo a ser administrado por todos, sendo que a sociedade majoritária precisa assumir seu papel. Papel esse que precisa, necessariamente, promover a Transdisciplinaridade através do ato de educar. 
ABSTRACT: In this article, we reflect about Transdisciplinarity and Intercultural Education, considering the context Apinayé. The Apinayé are an indigenous people of the northern state of Tocantins. The methodological aspects are directed to an interdisciplinary concept, covering theoretical and Field Research. For the development of the text, we have two phases that complement each other. First we review the literature regards the theme. For the concepts of Inter and Transdisciplinarity, we use the theoretical D'Ambrosio (1997); Fazenda (2003, 2006); Nicolescu (2008, 2009), Damas (2009), Magalhães (2009), and Sommerman (2005). For Intercultural Education Ouellet (1991, 2002), Banks (1993), Maher (2005, 2006), and Grupioni (2001, 2002). About Apinayé Nimuendaju (1983), Da Matta (1976), and Albuquerque (1999, 2007, 2009). About the type of interdisciplinary research, Vasconcelos (2009). About Teacher Training, Tardif (2002) and Pinho (2007). The field research was accomplished through an ethnography using participant observation as Erikson (1984), and André (2000). The data, collected in a form qualitative, were generated by daily field notes. The results point to a reality where transdisciplinarity manifests itself in the pedagogical practice of mother tongue teachers Apinayé.

KEYWORDS: Transdisciplinarity. Intercultural education. Training indigenous teacher.

\section{REFERÊNCIAS}

ALBUQUERQUE, F. E. Interdisciplinaridade x Interculturalidade: uma prática pedagógica Apinayé. Revista Cocar, Belém, v.3, n.6, p.19-30, jul./dez. 2009.

. Contribuição da Fonologia ao Processo de Educação Indígena Apinayé.

2007. 256f. Tese (Doutorado em Letras) - Faculdade de Letras. Universidade Federal Fluminense. Niterói, 2007.

Contato dos Apinayé de Riachinho e Bonito Com o Português: Aspectos Da Situação Sociolinguística. 1999. 164f. Dissertação (Mestrado em Linguística) Faculdade de Letras, Universidade Federal de Goiás. Goiânia, 1999.

ANDRÉ, M. Etnografia da prática escolar. 4.ed. Campinas: Papirus, 2000.

BANKS, J. On Multicultural Education: development, dimensions, and challenges. Phi Delta Kappan, Bloomington, US, v.75, n.1, p.22-28, sept. 1993.

BATISTA, H. de S. Quando as práticas se encontram: transdisciplinaridade e práxis pedagógica indígena. Disponível em:

<www.cetrans.com.br/artigos/Hildonice_de_Souza_Batista.pdf>. Acesso em: 12 jan. 2011.

BOURDIEU, P. A economia das trocas simbólicas. São Paulo: Perspectiva, 1992. 
BRASIL. Lei $\mathrm{n}^{\circ}$ 11.645, de 10 de março de 2008. Altera a Lei $\mathrm{n}^{0}$ 9.394, de 20 de dezembro de 1996, modificada pela Lei $\mathrm{n}^{0}$ 10.639, de 9 de janeiro de 2003, que estabelece as diretrizes e bases da educação nacional, para incluir no currículo oficial da rede de ensino a obrigatoriedade da temática "História e Cultura Afro-Brasileira e Indígena. Diário Oficial. Brasília, DF, 10 mar. 2008. Disponível em: <http://www.planalto.gov.br/ccivil_03/_ato2007-2010/2008/lei/l11645.htm>. Acesso em: 2 jan. 2011.

. Decreto $n^{\circ} 90.960$, de 14 de fevereiro de 1985. Declara de ocupação dos silvícolas, área de terras nos municípios de Tocantinópolis e Itaguatins, no Estado de Goiás, e dá outras providências. Projeto LexML. Disponível em: <http://www.lexml.gov.br/urn/urn:lex:br:federal:decreto:1985-02-14;90960>. Acesso em: 15 jan. 2011.

D’ AMBRÓSIO, U. Transdiciplinaridade. São Paulo: Palas Athena, 1997.

DA MATTA, R. Um mundo dividido: a estrutura social dos índios apinayé. Petrópolis: Vozes, 1976.

DAMAS, L. A. Interdisciplinaridade e Transdisciplinaridade: o jeito de educar na complexidade. In: SANTOS, J. S. (Org.). Competências Interdisciplinares. São Paulo: Xamã, 2009. p.21-44.

DELORS, J. Educação um tesouro a descobrir. São Paulo: Cortez, 1998.

ERICKSON, F. What makes school ethnography 'ethnographic'? Anthropology and Education Quarterly, Washington, US, v.15, p.51-66, 1984. Disponível:

<http://www.indiana.edu/ educy520/sec5982/week_4/erickson84.pdf>. Acesso em: 31 jan. 2014.

FAZENDA, I. C. A. Interdisciplinaridade: qual o sentido? São Paulo: Paulus, 2003.

2006.

Interdisciplinaridade: história, teoria e pesquisa. 13.ed. São Paulo: Papirus,

GRUPIONI, L. D. B. Contextualizando o campo da formação de professores indígenas no Brasil. In: GRUPIONI, L. D. B. (Org). Formação de professores indígenas:

repensando trajetórias. Brasília: MEC, 2006. p.39-68. Disponível em:

$<$ http://www.dominiopublico.gov.br/pesquisa/DetalheObraForm.do?select_action=\&co _obra=24180>. Acesso em: 30 jan. 2014.

. Experiências e desafios na formação de professores indígenas no Brasil.

Revista em Aberto. Brasília, v.20, n.76, p.13-18, fev. 2003.

Os povos indígenas e a escola diferenciada: comentários sobre alguns

instrumentais jurídicos internacionais. In: GRUPIONI, L. D. B.; VIDAL, L.; FISCHMANN, R. (Org.). Povos indígenas e tolerância construindo práticas de respeito e solidariedade. São Paulo: EDUSP, 2001. p.39-80. 
LOPES DA SILVA, A.; GRUPIONI, L. D. B. A Temática indígena na escola novos subsídios para professores de $\mathbf{1}^{\mathbf{0}}$. e $\mathbf{2}^{\mathbf{0}}$. Graus. 3.ed. Brasília: MEC; MARI; UNESCO, 2000. Disponível em:

<http://www.pineb.ffch.ufba.br/downloads/1244392794A_Tematica_Indigena_na_Esco la_Aracy.pdf $>$. Acesso em: 30 jan. 2014.

MAGALHÃES, S. M. O. Transdisciplinaridade e seus reflexos na formação de professores. In: GUIMARÃES, V. S. (Org.). Formação e Profissionalização Docente. Goiânia: PUC Goiás, 2009. p.61-97.

MAHER, T. M. Formação de Professores Indígenas: uma discussão introdutória. In: GRUPIONI, L. D. B. (Org.). Formação de professores indígenas: repensando trajetórias. Brasília: MEC, 2006. p.11-38. Disponível em:

$<$ http://www.dominiopublico.gov.br/pesquisa/DetalheObraForm.do?select_action=\&co _obra=24180>. Acesso em: 30 jan. 2014.

A criança indígena: do falar materno ao falar emprestado. In: FARIA, A. L. G.; MELLO, S. (Org.). O mundo da escrita no universo da pequena infância. Campinas: Autores Associados, 2005. p.75-108.

MARTINS, M. A. Transdisciplinaridade: discurso ou realidade? 2009. 121f. Dissertação (Mestrado em Educação) - Faculdade de Educação, Universidade de Sorocaba, Sorocaba, 2009.

MORAES, M. C. O paradigma educacional emergente. 10.ed. São Paulo: Papirus, 2004.

MORIN, E. Introdução ao pensamento complexo. 5.ed. Rio de Janeiro: Instituto Piaget, 2002.

NICOLESCU, B. Educação e Transdiciplinaridade. Brasília: UNESCO, 2009. O Manifesto da Transdiciplinaridade. São Paulo: Triom, 2008.

NIMUENDAJU, C. Os Apinayé. Belém, 1983. Boletim do Museu Paraense Emílio Goeldi.

OUELLET, F. L’éducation Interculturelle Et L’éducation À La Citoyenneté Quelques pistes pour s'orienter dans la diversité des conceptions. Faculté de théologie, d'éthique et de philosophie, université de Sherbrooke. VEI Enjeux, França, n.129, jun. 2002.

Disponível em: <http://documentation.reseau-

enfance.com/IMG/pdf/0140_interculturel_et_education_citoyennete.pdf>. Acesso em: 31 jan. 2014.

PINHO, M. J. de. Políticas de formação de professores: intenção e realidade. Goiânia: Cânone Editorial, 2007.

SILVA, D. J. da. O paradigma transdisciplinar: uma perspectiva metodológica para a pesquisa ambiental. In: WORKSHOP SOBRE INTERDISCIPLINARIDADE DO INPE, 1999, São José dos Campos. Anais eletrônicos... São José dos Campos: INPE, 
1999. Disponível em: <http://www.redebrasileiradetransdisciplinaridade.net/mod/> . Acesso em: $11 \mathrm{dez} .2010$

SOMMERMAN, A. Inter ou Transdisciplinaridade? São Paulo: Paulus, 2006.

TARDIF, M. Saberes docentes e formação profissional. Petrópolis, RJ: Vozes, 2002.

VASCONCELOS, E. M. Complexidade e pesquisa interdisciplinar: epistemologia e metodologia operativa. 4.ed. Petrópolis, RJ: Vozes, 2009.

WEIL, P. Rumo à nova Transdisciplinaridade: sistemas abertos de conhecimento. São Paulo: Summus, 1993. 